\title{
Abusive head trauma: an epidemiological and cost analysis
}

\author{
Scott Boop, MPH, ${ }^{1}$ Mary Axente, NP, ${ }^{2}$ Blakely Weatherford, NP, ${ }^{2}$ and Paul Klimo Jr., MD, MPH ${ }^{2-4}$ \\ ${ }^{1}$ College of Medicine, University of Arkansas for Medical Sciences, Little Rock, Arkansas; ${ }^{2}$ Neuroscience Institute, Le Bonheur \\ Children's Hospital; ${ }^{3}$ Department of Neurosurgery, University of Tennessee Health Science Center; and ${ }^{4}$ Semmes-Murphey \\ Neurologic \& Spine Institute, Memphis, Tennessee
}

OBJECTIVE Research on pediatric abusive head trauma (AHT) has largely focused on clinical presentation and management. The authors sought to review a single-institution experience from a public health perspective to gain a better understanding of the local population affected, determine overall incidence and seasonal trends, and provide details on the initial hospitalization, including extent of injuries, neurosurgical interventions, and hospital charges.

METHODS All cases of AHT involving patients who presented to Le Bonheur Children's Hospital (LBCH) from 2009 through 2014 were identified. AHT was defined as skull fracture or intracranial hemorrhage in a child under the age of 5 years with a suspicious mechanism or evidence of other intentional injuries, such as retinal hemorrhages, old or new fractures, or soft-tissue bruising. Injuries were categorized as Grade I (skull fracture only), Grade II (intracranial hemorrhage or edema not requiring surgical intervention), or Grade III (intracranial hemorrhage requiring intervention or death due to brain injury).

RESULTS Two hundred thirteen AHT cases were identified. The demographics of the study population are similar to those reported in the literature: the majority of the patients involved were 6 months of age or younger $(55 \%)$, male $(61 \%)$, African American (47\%), and publicly insured (82\%). One hundred one neurosurgical procedures were performed in 58 children, with the most common being bur hole placement for treatment of subdural collections $(25 \%)$ and decompressive hemicraniectomy (22\%). The annual incidence rate rose from 2009 (19.6 cases per 100,000 in the population under 5 years of age) to 2014 (47.4 cases per 100,000) and showed seasonal peaks in January, July, and October (6-year average single-month incidence, respectively, $24.7,21.7$, and 24.7 per 100,000). The total hospital charges were $\$ 13,014,584$, with a median cost of $\$ 27,939$. Treatment costs for children who required surgical intervention (i.e., those with Grade III) were up to 10 times those of children with less severe injuries.

CONCLUSIONS In the authors' local population, victims of AHT are overwhelmingly infants, are more often male than female, and are disproportionately from lower socioeconomic ranks. The incidence is increasing and initial hospitalization charges are substantial and variable. The authors introduce a simple 3-tiered injury classification scheme that adequately stratifies length of hospital stay and cost.

http://thejns.org/doi/abs/10.3171/2016.1.PEDS15583

KEY WORDS pediatric; children; abusive head trauma; non-accidental trauma

$\mathrm{H}$ EALTH care providers know all too well the immediate and long-term consequences of abusive head trauma (AHT). It is estimated to account for $80 \%$ of the deaths that result from childhood maltreatment, killing more than 250 children each year in the United States. ${ }^{14}$ Compared with patients with nonabusive head injury, children with AHT are more often younger than 1 year of age, male, and from socioeconomically disadvantaged families; they are also likely to be hospitalized longer and have higher rates of in-hospital mortality. ${ }^{18}$ Males (i.e., fathers, stepfathers, and boyfriends) continue to be the most likely perpetrators and generally inflict more serious cranial injuries than female perpetrators. But female babysitters represent a significantly large group (estimated $20 \%$ or more) of less-recognized offenders. ${ }^{4,19,23,27,28}$ AHT can result in skull fractures, intracranial hemorrhage (most commonly subdural hematomas), and strokes. Compared with accidental injuries, the subdural hematomas in AHT are more likely to have components of different ages suggesting repeated abuse-and to be interhemispheric or

ABBREVIATIONS AHT = abusive head trauma; CARES = Child Advocacy Resource and Evaluation Services; $\mathrm{Cl}=\mathrm{confidence} \mathrm{interval;} \mathrm{LBCH} \mathrm{=} \mathrm{Le} \mathrm{Bonheur} \mathrm{Children's}$ Hospital; LOS = length of hospital stay.

SUBMITTED September 29, 2015. ACCEPTED January 13, 2016.

INCLUDE WHEN CITING Published online July 12, 2016; DOI: 10.3171/2016.1.PEDS15583. 
within the posterior fossa. ${ }^{6,11}$ Approximately one-third of children who suffer AHT are severely disabled, another third are moderately disabled, and the final third have few to no consequences. ${ }^{17}$

A number of studies have evaluated the incidence and costs of AHT. In a recent review, the estimated average lifetime cost per victim of childhood abuse was $\$ 210,012$ (in 2010 US dollars). ${ }^{5}$ For victims who died of abuse, costs were even higher $(\$ 1,272,900)$, with $\$ 14,100$ in direct medical costs and $\$ 1,258,800$ in productivity losses. Calculations of the total lifetime economic burden resulting from new cases of fatal and nonfatal child maltreatment in the United States in 2008 range from $\$ 124$ billion to a staggering \$585 billion.

Memphis and the surrounding area (Shelby County) represent a unique opportunity to study this issue. With over a quarter of the population below the poverty line and nearly as many people with less than a high school education, children in this area are at high risk for abuse, including AHT (http://quickfacts.census.gov/qfd/states/47/4748000. $\mathrm{html}$ ). In this study, we aimed to comprehensively characterize the AHT population demographics in the geographic area served by Le Bonheur Children's Hospital (LBCH) and to calculate incidence rates and costs as determined by hospital charges.

\section{Methods}

\section{Database Creation and Outcome}

LBCH is a 255-bed children's hospital located in downtown Memphis, in the southwest corner of Tennessee. It serves a 200-mile radius and is the primary tertiary referral center for an estimated 1.4 million Mid-South children from 5 states: Tennessee, Mississippi, Arkansas, Kentucky, and Missouri. LBCH is a Level I pediatric trauma center for Tennessee, Mississippi, and Arkansas and the pediatric teaching partner of the University of Tennessee Health Science Center. The Child Advocacy Resource and Evaluation Services (CARES) team at LBCH evaluates all children with suspected AHT. We sought to identify all cases of AHT that were evaluated at LBCH from January 2009 through 2014. Cases of AHT were identified through several sources, including a prospectively maintained database of pediatric traumatic injuries (by the Trauma Service at LBCH) and an electronic medical record (EMR) query of all pediatric cases in which consultations were performed by members of both the neurosurgery service and CARES.

\section{Variables and Definitions}

For the purpose of this study, AHT was defined as skull fracture or intracranial hemorrhage in a child under the age of 5 years with a suspicious mechanism or evidence of other intentional injuries (i.e., retinal hemorrhages, old or new fractures, or soft-tissue bruising) that was consistent with AHT according to the final assessment of the CARES team. For each patient, we collected demographic information, including date of injury, race, and state of residence. Using recent local population statistics, we calculated monthly and annual incidence rates. The hospital course for each child was recorded, including extent of injury, length of hospital stay (LOS) and charges associated with that initial hospitalization, need for any neurosurgical intervention, and in-hospital mortality. For the purpose of this study, we viewed hospital "charges" and "cost" as having equivalent meanings (technically, "charges" are always greater than "costs," typically by a fixed factor ${ }^{7}$ ), although it should be noted that professional fees are not included in the hospital charges. Cases were subdivided into 3 groups based on injury type: Grade I, skull fracture alone with or without associated craniofacial soft-tissue injury; Grade II, intracranial hemorrhage (i.e., intraparenchymal, intraventricular, subarachnoid, or subdural) or cerebral edema not requiring surgical intervention; and Grade III, intracranial hemorrhage requiring neurosurgical intervention or death as a direct result of AHT.

\section{Study Questions}

With this retrospective observational study, we posed the following questions: What are the demographic and clinical characteristics of AHT cases that are managed at $\mathrm{LBCH}$ ? What are the monthly and annual incidence rates, and do those rates change with time or by season? What is the financial impact (i.e., hospital charges) of the child's injury for the hospital stay during which AHT was first diagnosed?

\section{Statistical Analysis}

Incidence rates were calculated by dividing the accrued number of events during a time interval (e.g., month or year) by the total $\mathrm{LBCH}$ catchment population for each interval. For monthly incidence rates, we averaged the rate for the month in question over the 6-year data that we acquired for this study. For example, the average rate for January is derived from January rates for the years 20092014. The catchment population was determined for each year from 2013 census data provided by LBCH marketing. A confidence interval (CI) was constructed for each month- and year-specific incidence rate, treating the rate as a Poisson random variable according to the following formula:

$$
95 \% C I=R_{t}\left(Z_{\left(1-\frac{\alpha}{2}\right)} \times \sqrt{\frac{R_{t}}{n_{t}}}\right)
$$

where $R_{t}$ is the month-specific rate and $n_{t}$ is the specific population for each month. Due to a lack of census data for each month, an average population measure for the 6-year interval was used. All incidence measures are reported for the 0- through 4-year age group. Cost data were available for 211 (99.1\%) of the cases. Basic descriptive statistics were calculated for these data. All data were analyzed using Microsoft Excel 2016.

\section{Results}

\section{Demographics and Hospital Course}

Two hundred thirteen children with AHT were evaluated and treated at $\mathrm{LBCH}$. The most common race was African American (47\%), and the majority of cases were 
male (61\%), 6 months of age or younger (55\%), publicly insured (82\%), and from Tennessee (60\%) (Table 1). The median age of our cases was 5.9 months (range 2 weeks-4 years). Overall, 54 (25.4\%) were found to have skull fractures without an intracranial hemorrhage (i.e., Grade I AHT); 102 (47.9\%) presented with an intracranial hemorrhage that did not require surgery (i.e., Grade II); and 57 $(26.8 \%)$ either presented with an intracranial hemorrhage that did require neurosurgical intervention $(n=50,87.7 \%)$, or died as a direct result of AHT $(n=7,12.3 \%)$ (i.e., Grade III). A summary of surgical procedures for these patients can be found in Table 2 . The most common procedures were bur hole evacuation of a subdural hemorrhage ( $\mathrm{n}=$ $25)$, decompressive craniectomy $(\mathrm{n}=22$, including 6 cases in which the bone flap was replaced during the same hospitalization), and percutaneous transfontanelle subdural taps $(n=20)$. The median LOS was 5 days (range 1-65 days) and the total LOS for all patients was 1,760 days. Median and total LOS showed an increase with increasing injury grade (Table 3 ).

\section{Incidence and Cost}

Table 4 and Figs. 1 and 2 provide numbers of the 3 different grades of injury and incidence stratified by month using aggregate data for the study period 2009-2014. Figure 2 depicts the monthly incidence rates for AHT. January, July, and October were associated with higher than average rates $(24.7,21.7$, and 24.7 per 100,000 , respectively). Conversely, April, September, and November showed consistently low rates throughout this period (11.3, 16.5, and 12.4 per 100,000, respectively). Table 5 and Figs. 3 and 4 present annual data, which show an overall increase from 19.6 per 100,000 in 2009 to 47.4 per 100,000 in 2014 (with the highest incidence being in 2012, at 49.5 per 100,000) (Fig. 4).

The total cost for all cases was calculated as $\$ 13,014,584$, and the median cost per case was $\$ 27,939$ (range $\$ 1,189$ $\$ 385,688$ ). The 1- to 6-month age group showed the highest total charges, yet older children (13-24 months and 2-5 years) showed higher median charges as a group (Table 6). Although summer months still showed high total costs overall, January had the largest median cost overall. The most costly year was 2012 , with $\$ 3,012,400$ in total charges. Individuals with public insurance incurred the majority of costs, though the median cost was similar for the different coverage groups. Individuals with Grade III injuries incurred higher costs than those with Grade II or Grade I injuries: 1.5-10.2 times the cost of total charges and 2.9-7.3 times the median cost (Table 6).

\section{Discussion \\ Our Results}

Whereas many prior studies have viewed AHT from a state or nationwide perspective, $3,13,20,24,25,29,31$ our study was designed to examine the disease through the lens of a single hospital to provide a local epidemiological perspective. AHT is disproportionately a malady of the poor. ${ }^{18}$ There are many risk factors associated with socioeconomic status that could contribute to this particular finding, including drug use or abuse, single-parent households, young maternal or paternal age, low education lev-
TABLE 1. Description of patient demographics $(n=213)$

\begin{tabular}{cc}
\hline \multicolumn{1}{c}{ Variable } & No. of Patients (\%) \\
\hline Race & $82(39)$ \\
\hline White & $101(47)$ \\
\hline African American & $30(14)$ \\
\hline Other & $129(61)$ \\
\hline Sex & $84(39)$ \\
\hline Male & $7(3)$ \\
\hline Female & $111(52)$ \\
\hline Age & $53(25)$ \\
\hline$<1$ mo & $25(12)$ \\
\hline $1-6$ mos & $17(8)$ \\
\hline $7-12$ mos & \\
\hline $13-24$ mos & $127(60)$ \\
\hline 24 mos-5 yrs & $24(11)$ \\
\hline State of origin & $55(26)$ \\
\hline Tennessee & $5(2)$ \\
\hline Arkansas & $2(1)$ \\
\hline Mississippi & $27(13)$ \\
\hline Missouri & $175(82)$ \\
\hline Kentucky & $11(5)$ \\
\hline Insurance status &
\end{tabular}

els, and high psychosocial stress levels. ${ }^{13}$ Consistent with prior reports, ${ }^{32}$ the AHT population treated at $\mathrm{LBCH}$ was predominantly male, African American, very young (the largest age group was 1-6 months), and publicly insured. Wood et al.$^{30}$ have suggested that a bias may exist in evaluation for AHT and that African American or publicly in-

TABLE 2. Description of surgical procedures $(n=101)$ performed in 58 children with Grade III injuries

\begin{tabular}{cc}
\hline \multicolumn{1}{c}{ Description } & No. of Procedures (\%) \\
\hline Decompressive hemicraniectomy & $22(22)$ \\
\hline Bone flap replacement/cranioplasty & 6 \\
\hline Craniotomy for evacuation of ICH & $9(9)$ \\
\hline Bur hole evacuation of SDH & $25(25)$ \\
\hline With drain & 16 \\
\hline Without drain & 9 \\
\hline ICP monitor & $9(9)$ \\
\hline Bolt & 3 \\
\hline EVD & 6 \\
\hline Shunt & $12(12)$ \\
\hline Subduroperitoneal & 9 \\
\hline Ventriculoperitoneal & 3 \\
\hline Transfontanelle subdural taps & $20(20)$ \\
\hline Lumbar puncture & $4(4)$ \\
\hline
\end{tabular}

$E V D=$ external ventricular drain; $I C H$ = intracranial hemorrhage; $I C P=$ intracranial pressure; $\mathrm{SDH}=$ subdural hemorrhage. 
TABLE 3. Length of hospital stay stratified by injury grade

\begin{tabular}{cccc}
\hline & \multicolumn{3}{c}{ LOS (days) } \\
\cline { 2 - 4 } Injury Grade & Total & Median & Range \\
\hline I & 167 & 3 & $1-7$ \\
\hline II & 770 & 5 & $1-46$ \\
\hline III & 823 & 10.5 & $2-65$ \\
\hline
\end{tabular}

sured/uninsured infants may be overevaluated compared with white or privately insured children. While we cannot definitively prove or disprove their theory within our own population, we can say that great care is taken to evaluate all children suspected of having AHT through independent evaluation by multiple services (e.g., general pediatrics, emergency room, general surgery), with the final decision being rendered by the CARES team. As expected, the majority of our cases came from Tennessee (predominantly Shelby County), but it is interesting to note that from 2009 through 2014 there was a substantial increase in the numbers of AHT cases from Arkansas and Mississippi as well as Tennessee; there were too few cases from Missouri or Kentucky to be able to allow for identification of trends. This may be a result of improved general awareness and a low threshold for evaluation, in addition to the designation of $\mathrm{LBCH}$ as a Level I trauma center during the study period (October 2011). However, a change in referral patterns as a result of the Level I trauma center designation is unlikely to be the sole-or even the predominant-reason for the substantial increase in the AHT incidence from 2009 (19.6 per 100,000) through 2014 (47.4 per 100,000), because our hospital has always been the only tertiary facility with pediatric neurosurgical services for a catchment area that has not experienced any dramatic population shifts. This leads us to believe that while completely accurate rates are difficult to obtain, the increase in AHT is most likely a real phenomenon.

Fifty-eight children required 101 surgical or bedside procedures, with the majority of them being directed at the management of subdural collections, which is in agreement with other publications. ${ }^{15}$ Our mortality rate was 3.3\% (7 of 213 patients); all of the patients who died had subdural hematomas with widespread areas of bilateral cerebral infarction and poor neurological examination findings at presentation. Our mortality rate was significantly lower than the rates in other reports, such as those of Scribano et al. (19\%), ${ }^{23}$ Esernio-Jenssen et al. (18\%), ${ }^{4}$ and King et al. (19\%). ${ }^{13}$ Shein et al. ${ }^{26}$ found that a low initial Glasgow Coma Scale score, retinal hemorrhages, intraparenchymal hemorrhage, and cerebral edema are independent predictors of mortality in AHT.

Many studies have provided incidence rates.$^{20}$ For example, Selassie et al. reported age-specific rates per 100,000 per year ranging from 28.9 in infants to 4.1 in 5-year-olds. ${ }^{24}$ Narang and Clarke ${ }^{17}$ estimated the incidence to be between 16 and 33 cases per 100,000 children per year in the first 2 years of life. Using both the narrow and broad coding algorithms of the Centers for Disease Control and Prevention, Shanahan et al. determined the incidence to be, respectively, 33.4 and 38.8 cases per 100,000 children younger than 1 year of age per year. ${ }^{25}$ Similarly, Niederkrotenthaler et al. ${ }^{18}$

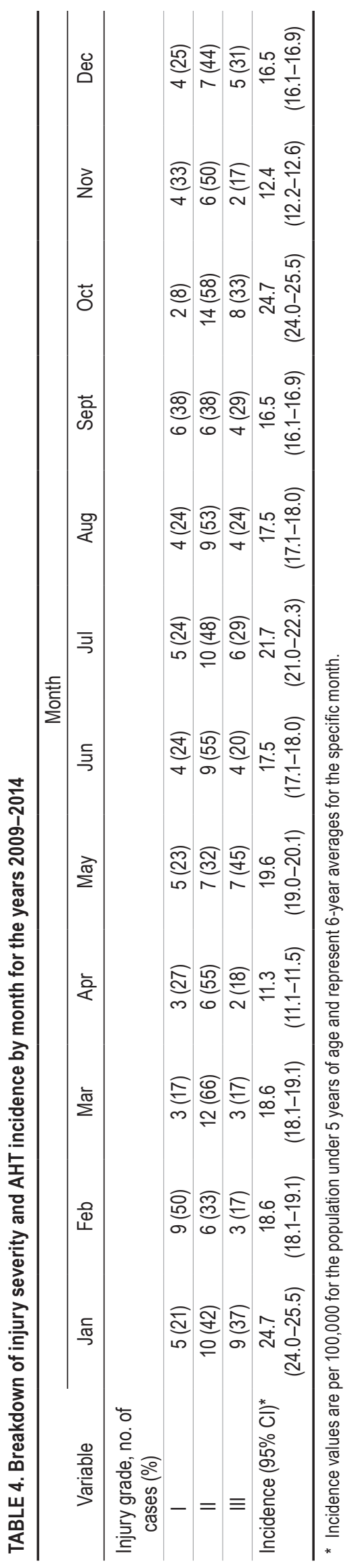

J Neurosurg Pediatr Volume $18 \cdot$ November 2016 


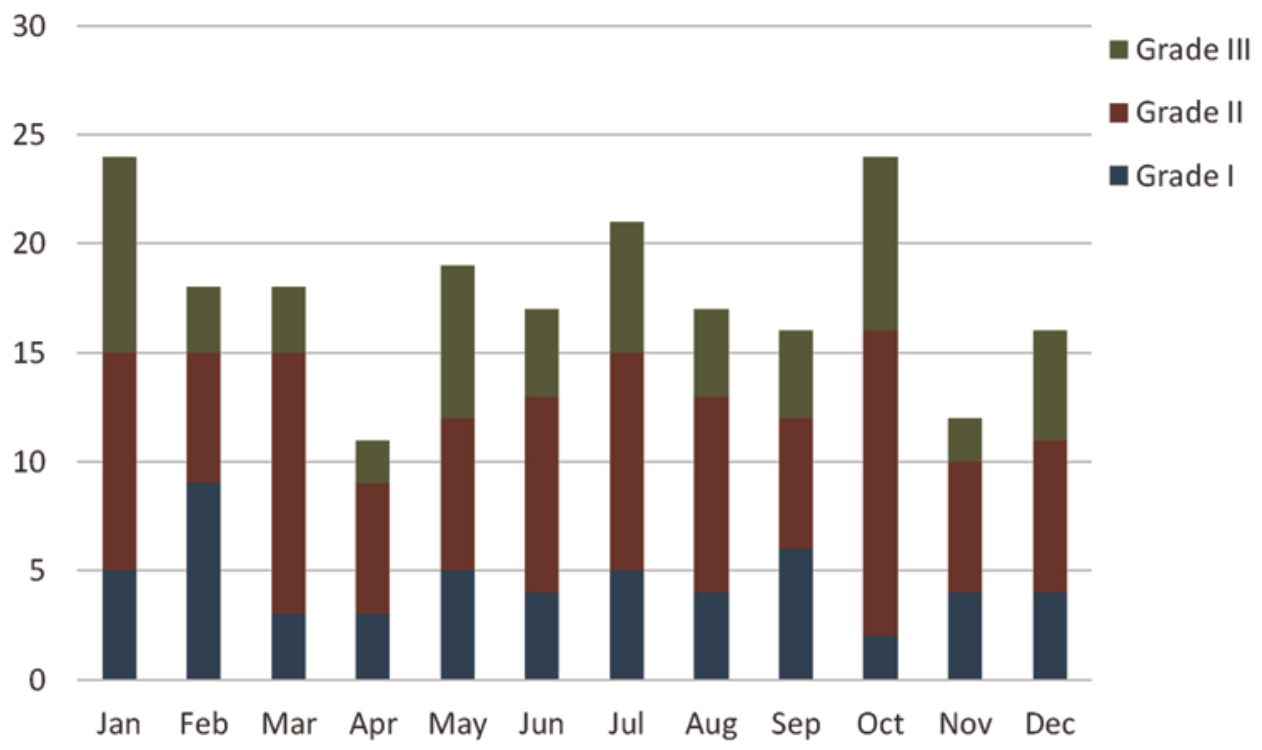

FIG. 1. Injury severity by month using aggregate data from 2009 through 2014. Grade I = skull fracture without intracranial hemorrhage $(\mathrm{ICH})$; Grade II = ICH not requiring surgery; Grade III = ICH requiring neurosurgical intervention or AHT directly resulting in death. Figure is available in color online only.

reported a US incidence rate of 39.8 per 100,000 per year for children younger than 1 year and 6.8 per 100,000 per year for children 1 year old. Using emergency department data for the years 2006-2009, Xiang et al..$^{32}$ calculated a risk that was directly comparable to ours but significantly lower (i.e., 12.83 per 100,000 per year for children 4 years of age or younger) than our average annual incidence of 36.6 cases per 100,000 children per year. To our knowledge, ours is the first study comparing AHT incidence rates across individual months and years. Our average monthly (6-year aggregate) incidence of abusive head injury in the catchment area per 100,000 children 0-4 years of age was 18.3 cases. In general, late spring and summer (i.e., May to August) had higher rates, with the months of October and January having the highest (both 24.7). This could be partially attributed to single years, 2013 and 2014, which had an unusually large number of cases in October and January, respectively. It is possible that if we had conducted our study over a longer time period, the differences in the monthly/seasonal rates would have washed out, as we can think of no obvious reason why AHT would vary by month or season, unlike nonabusive head trauma in both children and adults. Unfortunately, there does appear to be a clear increase in the annual incidence of AHT at $\mathrm{LBCH}$, but the reasons for this are not readily apparent.

There has also been considerable interest in the costs

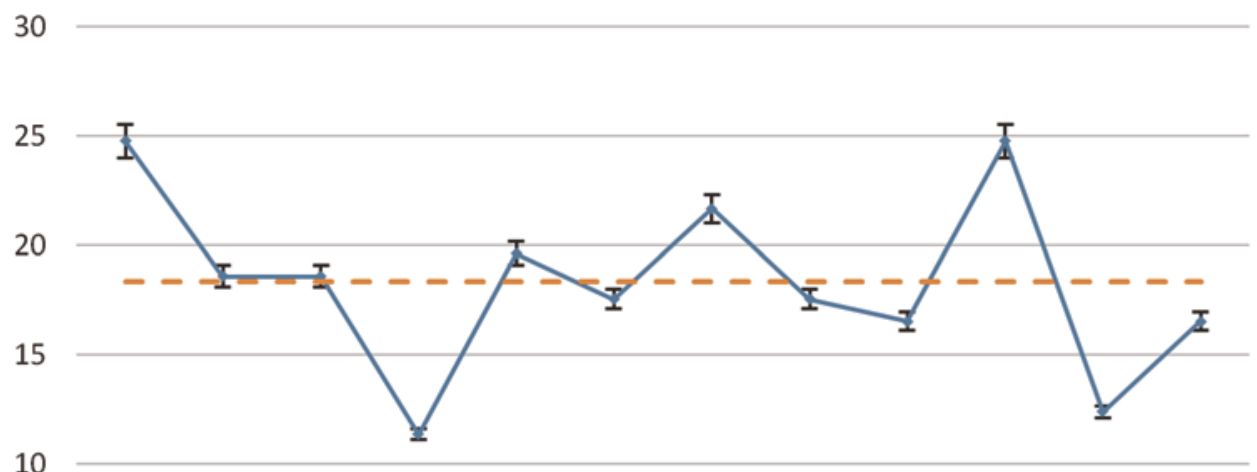

10

5

0

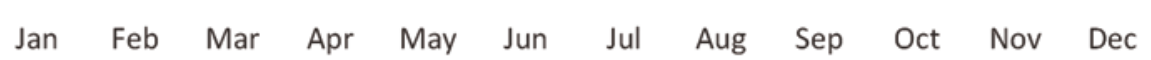

FIG. 2. Monthly AHT incidence with $95 \% \mathrm{Cl}(2009-2014)$. Dotted red line represents overall average rate for the 6 years (18.3 per $100,000)$. Figure is available in color online only. 
TABLE 5. Breakdown of injury severity and AHT incidence by year

\begin{tabular}{lcccccc}
\hline & \multicolumn{5}{c}{ Year } \\
\cline { 2 - 7 } \multicolumn{1}{c}{ Variable } & 2009 & 2010 & 2011 & 2012 & 2013 & 2014 \\
\hline Injury grade, no. of cases (\%) & & & & & \\
\hline I & $4(21)$ & $6(24)$ & $12(32)$ & $10(21)$ & $9(24)$ & $13(28)$ \\
\hline II & $9(47)$ & $9(36)$ & $20(53)$ & $23(48)$ & $19(52)$ & $22(48)$ \\
\hline III & $6(32)$ & $10(40)$ & $6(16)$ & $15(31)$ & $9(24)$ & $11(24)$ \\
\hline Incidence $(95 \% \mathrm{Cl})^{*}$ & $19.6(19.0-21.1)$ & $25.8(25.0-26.6)$ & $39.2(37.6-40.7)$ & $49.5(47.3-51.7)$ & $38.2(36.7-39.6)$ & $47.4(45.4-49.5)$ \\
\hline
\end{tabular}

* Incidence values are per 100,000 for the population under 5 years of age.

associated with AHT. ${ }^{5,8,21}$ To our knowledge, this is the first study to look at how injury severity correlates with the economic burden associated with AHT as measured by hospital charges. We have introduced a novel, simple injury classification (Grades I-III) that can be used to stratify not only injury severity but also associated surrogate variables of cost and LOS data. This attempt was undertaken because a review of the AHT literature revealed no such unifying classification system. Our system is analogous to the Hunt and Hess grading system used for patients with aneurysmal subarachnoid hemorrhage. ${ }^{10} \mathrm{It}$ is our hope that our classification system will be scrutinized, modified, and used by others to create a common terminology for future AHT research.

Not surprisingly, our results show clear increases in the costs of treatment associated with increasing severity of injury-Grade III injuries having 10-fold higher cumulative costs than those of Grade I, despite having similar numbers of patients categorized into these 2 groups. Even though the number of patients with Grade II injuries was nearly twice the number of patients with Grade III injuries (114 vs 70), the total costs for Grade II injuries were still far lower. The distribution of LOS data for different injurygrade groups was similar to that of cost data. Patients with Grade III injuries accumulated over 4-fold more hospital days than those with Grade I injuries and the number of hospital days required for Grade III and Grade II injuries was similar, despite the fact that the group with Grade II injuries included twice as many patients. It should be noted that the total number of hospital days for Grade III injuries is skewed downward by patients who died while

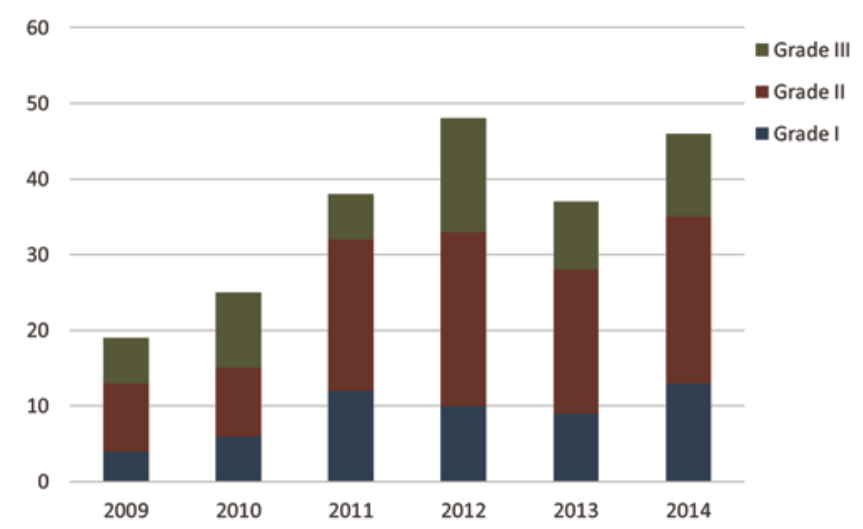

FIG. 3. Injury severity by year using aggregate data from 2009 through 2014. Figure is available in color online only. under care, the majority of whom were only admitted 1 day before death. The median cost of a single admission for AHT during the study period was nearly $\$ 28,000$, and the total hospital charges were a staggering \$13 million.

Like all studies, ours has advantages and disadvantages. While our population is much smaller than those studies that use national administrative databases, such as the Kids' Inpatient Database,${ }^{19}$ we were able to provide greater clinical detail and did not rely on International Classification of Diseases (ICD) codes that such registries are based on. ${ }^{12,16,25}$ We are confident our search strategy identified the vast majority of AHT cases, but we may have missed a few. It is possible that we may have missed more older cases (e.g., from 2009 or 2010) than recent ones (e.g., from 2013 or 2014). Nonetheless, it is unlikely that any significant number of children were managed at hospitals other than $\mathrm{LBCH}$, particularly in Shelby and other immediate surrounding counties. Beyond these counties, it is possible that some children were managed at other tertiary children's hospitals with pediatric neurosurgical services. Another issue concerns our assessment of AHT incidence, which was calculated using population estimates and projections due to the fact that no reliable monthly or yearly population counts exist for our study population, although there has been no dramatic change in the population over the study period. The figures that we present should thus be regarded as fairly accurate estimates. Our most notable limitation is that our analysis pertained to the child's initial admission. There will always be a need for longitudinal studies evaluating cost, neurological development, disability and recovery, school performance, and psychoso-

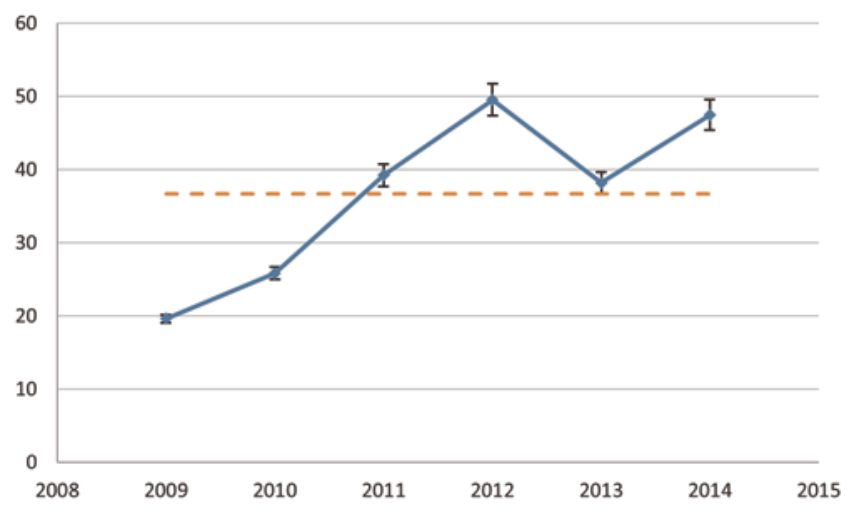

FIG. 4. Yearly AHT incidence with $95 \% \mathrm{Cl}(2009-2014)$. Dotted red line represents overall average rate for the 6 years $(36.6$ per 100,000). Figure is available in color online only. 
TABLE 6. Total and median costs for patient subgroups

\begin{tabular}{|c|c|c|}
\hline Variable & $\begin{array}{l}\text { Total Cost for Variable } \\
\text { (US \$) }\end{array}$ & Median Cost (US \$) \\
\hline \multicolumn{3}{|l|}{ Race } \\
\hline African American & $6,313,532$ & 31,053 \\
\hline White & $4,320,298$ & 23,782 \\
\hline Other & $2,380,753$ & 38,872 \\
\hline \multicolumn{3}{|l|}{ Age } \\
\hline$<1 \mathrm{mo}$ & 152,602 & 15,898 \\
\hline $1-6$ mos & $6,691,326$ & 29,047 \\
\hline $7-12$ mos & $2,553,420$ & 20,910 \\
\hline $13-24$ mos & $1,795,032$ & 34,413 \\
\hline 24 mos-5 yrs & $1,822,202$ & 45,950 \\
\hline \multicolumn{3}{|l|}{ Month } \\
\hline Jan & $1,951,002$ & 45,356 \\
\hline Feb & 879,666 & 19,869 \\
\hline Mar & 730,487 & 25,641 \\
\hline Apr & 483,006 & 26,339 \\
\hline May & $1,642,253$ & 25,860 \\
\hline Jun & $1,059,261$ & 26,844 \\
\hline Jul & $1,316,166$ & 31,032 \\
\hline Aug & $1,292,273$ & 32,838 \\
\hline Sep & 691,734 & 20,025 \\
\hline Oct & $1,409,196$ & 33,471 \\
\hline Nov & 730,764 & 35,352 \\
\hline Dec & 829,136 & 31,053 \\
\hline \multicolumn{3}{|l|}{ Year } \\
\hline 2009 & 899,895 & 30,855 \\
\hline 2010 & $1,895,584$ & 46,439 \\
\hline 2011 & $1,914,596$ & 22,839 \\
\hline 2012 & $3,012,400$ & 26,899 \\
\hline 2013 & $2,696,110$ & 34,589 \\
\hline 2014 & $2,595,998$ & 20,297 \\
\hline \multicolumn{3}{|l|}{ Insurance status } \\
\hline Private & $1,688,782$ & 32,374 \\
\hline Public & $10,680,233$ & 27,288 \\
\hline None & 645,569 & 17,244 \\
\hline \multicolumn{3}{|l|}{ Injury severity } \\
\hline Grade I & 716,628 & 12,314 \\
\hline Grade II & $4,977,020$ & 30,819 \\
\hline Grade III & $7,320,936$ & 90,092 \\
\hline
\end{tabular}

cial behavior. ${ }^{9,22}$ For example, Peterson et al. estimated the total medical cost attributable to AHT in the 4 years after diagnosis as $\$ 47,952$ (95\% CI $\$ 40,219-\$ 55,685))^{21}$ Interventions targeting known risk factors, such as parenting education for the stress of inconsolable infant crying, have demonstrated good levels of success in fighting pediatric AHT.,2

\section{Conclusions}

Abusive head trauma continues to be a major public health disease in the US. It requires a rigorous, multidisciplinary approach, with pediatric neurosurgery playing a major role. We have reviewed our 6-year experience, identifying 213 cases. Demographic characteristics of our population are similar to those reported in other studies. Our average annual incidence was 36.6 cases per 100,000 children under the age of 5 years, with a steady increase over the study period. The months that showed the highest number of cases were January and October. The median cost of a single admission was nearly $\$ 28,000$ and the total hospital charges were $\$ 13$ million. We introduce a simple 3 -tiered injury classification system that stratifies injury severity, cost, and LOS.

\section{Acknowledgments}

We wish to thank Andrew J. Gienapp (Department of Medical Education, Methodist University Hospital, and Department of Neurosurgery, University of Tennessee Health Science Center, Memphis, Tennessee) for technical and copy editing, preparation of the manuscript and figures for publishing, and publication assistance with this manuscript. We would also like to thank Lydia Smith and Kim Giles (Le Bonheur Neuroscience Center) for assisting us in our patient search strategy and providing hospital charges.

\section{References}

1. Altman RL, Canter J, Patrick PA, Daley N, Butt NK, Brand DA: Parent education by maternity nurses and prevention of abusive head trauma. Pediatrics 128:e1164-e1172, 2011

2. Dias MS, Smith K, DeGuehery K, Mazur P, Li V, Shaffer ML: Preventing abusive head trauma among infants and young children: a hospital-based, parent education program. Pediatrics 115:e470-e477, 2005

3. Díaz-Olavarrieta C, García-Piña CA, Loredo-Abdala A, Paz F, Garcia SG, Schilmann A: Abusive head trauma at a tertiary care children's hospital in Mexico City. A preliminary study. Child Abuse Negl 35:915-923, 2011

4. Esernio-Jenssen D, Tai J, Kodsi S: Abusive head trauma in children: a comparison of male and female perpetrators. Pediatrics 127:649-657, 2011

5. Fang X, Brown DS, Florence CS, Mercy JA: The economic burden of child maltreatment in the United States and implications for prevention. Child Abuse Negl 36:156-165, 2012

6. Feldman KW, Sugar NF, Browd SR: Initial clinical presentation of children with acute and chronic versus acute subdural hemorrhage resulting from abusive head trauma. J Neurosurg Pediatr 16:177-185, 2015

7. Finkler SA: The distinction between cost and charges. Ann Intern Med 96:102-109, 1982

8. Friedman J, Reed P, Sharplin P, Kelly P: Primary prevention of pediatric abusive head trauma: a cost audit and cost-utility analysis. Child Abuse Negl 36:760-770, 2012

9. Greiner MV, Lawrence AP, Horn P, Newmeyer AJ, Makoroff KL: Early clinical indicators of developmental outcome in abusive head trauma. Childs Nerv Syst 28:889-896, 2012

10. Hunt WE, Hess RM: Surgical risk as related to time of intervention in the repair of intracranial aneurysms. J Neurosurg 28:14-20, 1968

11. Kemp AM, Jaspan T, Griffiths J, Stoodley N, Mann MK, Tempest V, et al: Neuroimaging: what neuroradiological features distinguish abusive from non-abusive head trauma? A systematic review. Arch Dis Child 96:1103-1112, 2011

12. Kestle JR: Administrative database research. J Neurosurg 122:441-442, 2015

13. King WJ, MacKay M, Sirnick A: Shaken baby syndrome in 
Canada: clinical characteristics and outcomes of hospital cases. CMAJ 168:155-159, 2003

14. Lopes NR, Eisenstein E, Williams LC: Abusive head trauma in children: a literature review. J Pediatr (Rio J) 89:426433, 2013

15. Melo JR, Di Rocco F, Bourgeois M, Puget S, Blauwblomme T, Sainte-Rose C, et al: Surgical options for treatment of traumatic subdural hematomas in children younger than 2 years of age. J Neurosurg Pediatr 13:456-461, 2014

16. Michael LM II, Klimo P: Outcomes research in neurosurgery: do administrative databases hold the answers? World Neurosurg 84:1193-1195, 2015

17. Narang S, Clarke J: Abusive head trauma: past, present, and future. J Child Neurol 29:1747-1756, 2014

18. Niederkrotenthaler T, Xu L, Parks SE, Sugerman DE: Descriptive factors of abusive head trauma in young childrenUnited States, 2000-2009. Child Abuse Negl 37:446-455, 2013

19. Nuño M, Pelissier L, Varshneya K, Adamo MA, Drazin D: Outcomes and factors associated with infant abusive head trauma in the US. J Neurosurg Pediatr 16:515-522, 2015

20. Parks S, Sugerman D, Xu L, Coronado V: Characteristics of non-fatal abusive head trauma among children in the USA, 2003-2008: application of the CDC operational case definition to national hospital inpatient data. Inj Prev 18:392-398, 2012

21. Peterson C, Xu L, Florence C, Parks SE, Miller TR, Barr RG, et al: The medical cost of abusive head trauma in the United States. Pediatrics 134:91-99, 2014

22. Risen SR, Suskauer SJ, Dematt EJ, Slomine BS, Salorio CF: Functional outcomes in children with abusive head trauma receiving inpatient rehabilitation compared with children with nonabusive head trauma. J Pediatr 164:613-619, 619. e1-619.e2, 2014

23. Scribano PV, Makoroff KL, Feldman KW, Berger RP: Association of perpetrator relationship to abusive head trauma clinical outcomes. Child Abuse Negl 37:771-777, 2013

24. Selassie AW, Borg K, Busch C, Russell WS: Abusive head trauma in young children: a population-based study. J Trauma Nurs 21:72-82, 2014

25. Shanahan ME, Zolotor AJ, Parrish JW, Barr RG, Runyan DK: National, regional, and state abusive head trauma: application of the CDC algorithm. Pediatrics 132:e1546-e1553, 2013

26. Shein SL, Bell MJ, Kochanek PM, Tyler-Kabara EC, Wisniewski SR, Feldman K, et al: Risk factors for mortality in children with abusive head trauma. J Pediatr 161:716-722, 722.e1, 2012

27. Starling SP, Holden JR: Perpetrators of abusive head trauma: a comparison of two geographic populations. South Med J 93:463-465, 2000

28. Starling SP, Holden JR, Jenny C: Abusive head trauma: the relationship of perpetrators to their victims. Pediatrics 95:259-262, 1995

29. Talvik I, Metsvaht T, Leito K, Põder H, Kool P, Väli M, et al: Inflicted traumatic brain injury (ITBI) or shaken baby syndrome (SBS) in Estonia. Acta Paediatr 95:799-804, 2006

30. Wood JN, Hall M, Schilling S, Keren R, Mitra N, Rubin DM: Disparities in the evaluation and diagnosis of abuse among infants with traumatic brain injury. Pediatrics 126:408-414, 2010

31. Xia X, Xiang J, Shao J, Smith GA, Yu C, Zhu H, et al: Characteristics and trends of hospitalized pediatric abuse head trauma in Wuhan, China: 2002-2011. Int J Environ Res Public Health 9:4187-4196, 2012

32. Xiang J, Shi J, Wheeler KK, Yeates KO, Taylor HG, Smith GA: Paediatric patients with abusive head trauma treated in US Emergency Departments, 2006-2009. Brain Inj 27:1555-1561, 2013

\section{Disclosures}

The authors report no conflict of interest concerning the materials or methods used in this study or the findings specified in this paper.

\section{Author Contributions}

Conception and design: Klimo, Boop. Acquisition of data: Boop, Axente, Weatherford. Analysis and interpretation of data: Klimo, Boop. Drafting the article: Klimo, Boop. Critically revising the article: Klimo. Reviewed submitted version of manuscript: Boop. Approved the final version of the manuscript on behalf of all authors: Klimo. Statistical analysis: Boop. Administrative/techni$\mathrm{cal} /$ material support: Axente, Weatherford. Study supervision: Klimo.

\section{Correspondence}

Paul Klimo Jr., Semmes-Murphey Neurologic \& Spine Institute, 6325 Humphreys Blvd., Memphis, TN 38120. email: pklimo@ semmes-murphey.com. 